\title{
Experimental and Numerical Study of the EOR Potential in Liquid-Rich Shales by Cyclic Gas Injection
}

\author{
Tao Wan, Yang Yu, James J. Sheng, Texas Tech University \\ Texas Tech University, Bob L. Herd Department of Petroleum Engineering, Box 43111, Lubbock, TX 79409-3111.
}

Tel: 806.834.8477 Fax: 806.742.3502 Email: tao.wan@ttu.edu

\begin{abstract}
One of the limitations of gas or water injection in tight shale oil reservoirs is that the fluid injectivity is low due to the nature of very low permeability of shale. Another challenge of gas flooding is that the injected gas is subject to early breakthrough in densely fractured shale gas or oil reservoirs, resulting in poor performance. Cyclic gas injection (CGI) in a single horizontal well is not affected by early gas breakthrough. Compared to gas flooding, cyclic gas injection is an effective recovery process in tight shale oil reservoirs. This paper presented our experimental work on using nitrogen cyclic injection in shale rocks. We analyzed the experimental data using numerical simulation approaches. Coreflooding and simulation outputs showed that it is favorable to implement cyclic gas injection enhanced oil recovery process in shale oil reservoirs.

Our experimental data and simulation results have demonstrated the potential of gas huff-n-puff injection to improve oil recovery in shale oil reservoirs. We also examined the effect of diffusion on improved oil recovery performance by cyclic injection process. The objective of this paper is to investigate significance of possible factors on gas huffn-puff recovery process in shale oil reservoirs via experimental work and simulation approaches. Our simulation results benchmarked with experimental observations showed that molecular diffusion played a significant role in the mobilization of oil in lab scale.
\end{abstract}

\section{Keywords}

Liquid-Rich shales; Enhanced oil recovery; Cyclic nitrogen injection; Huff-n-puff, Experimental data; Diffusion effect

\section{Introduction}

Monger and Coma (1988) conducted a laboratory-scale evaluation of the $\mathrm{CO}_{2}$ huff-n-puff (also called cyclic gas injection) process with 32 experiments. The significance of soak periods on the ultimate oil recovery is identified. The inclusion of a soak period led to an incremental oil recovery of $10 \%$ than in absence of soak periods. The soak periods are characterized by injected gas in the fracture transporting to the shale matrix by diffusion process. Experimental results by Shayegi et al. (1996) revealed that the first cycle yielded highest oil recovery. A second cycle recovered additional incremental oil with some decline in process efficiency. Laboratory results by Monger et al. (1991) showed that more favorable recovery performance is achieved by $\mathrm{CO}_{2}$ huff-n-puff injection at nearmiscible conditions than miscible. Their experimental data and reported field test results suggest that $\mathrm{CO}_{2}$ retention and $\mathrm{CO}_{2}$ utilization factor increases as pressure decreases. The conclusion was made under the presumption of same mass of $\mathrm{CO}_{2}$ injection. The recovery performance by a large $\mathrm{CO}_{2}$ slug injection that develops miscibility with reservoir oil is more favorable than a small $\mathrm{CO}_{2}$ slug.

Most of the available literature on performance of cyclic gas injection focused on reservoir conditions that have high permeability. Recent studies (Chen et al. 2014; Gamadi, et al. 2013; Wan et al. 2013) showed that cyclic gas injection could be a viable method to improve the oil recovery in shale oil reservoirs. Simulation results showed cyclic gas injection combined with modern technologies such as horizontal well drilling and hydraulic fracturing has 
achieved promising recovery results in low permeability formation. Kovscek et al. (2008) presented a series of experimental results of using $\mathrm{CO}_{2}$ injection to improve oil recovery in low permeability shale rocks $(0.02-1.3 \mathrm{mD})$. Countercurrent flow and concurrent injection schemes were employed to evaluate the oil recovery potential. Their experimental results showed that the incremental oil recovery from near miscible $\mathrm{CO}_{2}$ injection is around $35 \%$, in which $25 \%$ oil recovery obtained for the countercurrent flow mode and $10 \%$ for the concurrent flow. Wang et al. (2013) reported experimental results of $\mathrm{CO}_{2}$ huff-and-puff process operated in a $973 \mathrm{~mm}$ long composite core with an average permeability of $2.3 \mathrm{mD}$. Their experimental results showed that the first operation cycle contributes above half of the total oil production and additional oil produced from subsequent cycles is significantly decreased compared to previous cycles. Kurtoglu (2013) evaluated the feasibility of enhanced oil recovery by conventional gas injection and gas huff-n-puff in Bakken fields using simulation techniques. He used a dual-porosity reservoir model to simulate the $\mathrm{CO}_{2}$ huff-n-puff flooding performance in the Bakken field. Unfortunately, the diffusion effect was not included in their model because of numerical convergence issues. However, studies (Javadpour et al. 2007; Sakhaee-Pour and Bryant 2012; Ozkan et al. 2010) suggest that molecular diffusion is an important recovery mechanism in the mobilization and recovery of oil in very low permeability shale oil or gas reservoirs. Chen et al. (2014) investigated the effect of reservoir heterogeneity on $\mathrm{CO}_{2}$ huff-n-puff recovery process using (UT-COMP) simulation approaches, but there is no sound laboratory or field data to support the model prediction. Gamadi et al. (2013) presented a series of experimental data of cyclic gas injection in Barnett, Mancos and Eagle Ford shale cores. They investigated the effect of injection pressure, soaking time and the number of injection cycles on oil recovery performance by $\mathrm{N}_{2}$ huff-n-puff process.

The available literature provides limited information for the laboratory examination of the applicability of gas huffn-puff in very low permeability shale rocks. Very limited field or laboratory data are available on the performance of cyclic gas injection in shale oil reservoirs. The purpose of this paper is to extend earlier work performed by our research group (Gamadi et al., 2013). In this paper, we examined the relevant parameters that affect the performance of cyclic gas injection process in detail. The principle recovery mechanisms in shale oil reservoirs were discussed. We performed a series of experiments using immiscible cyclic nitrogen injection in Eagle Ford shale cores. The gas huff-n-puff corefloods were conducted with the same 2-in long, 1.5-in diameter Eagle Ford shale cores. This paper interrelated numerical simulation approach with the laboratory data to analyze the significance of possible parameters that have on the performance of cyclic injection recovery process.

\section{Material and Methods}

\subsection{Experimental Design}

All the experiments were performed at the temperature of $95{ }^{\circ} \mathrm{F}$ in the oven. To make sure the effect of studied variables is not affected by the variation of temperature, it is essential to maintain a constant temperature. We chose $95{ }^{\circ} \mathrm{F}$ because it is close to the room temperature, so it is convenient to operate. The cores used in current experiments are from the Eagle Ford. Each core has the same dimension with 1.5-inch in diameter and 2-inch in length. A mineral oil Soltrol-130 was used to represent the reservoir fluids. Table 1 shows the basic properties of Soltrol-130 provided by the manufacturer.

\begin{tabular}{|c|c|}
\hline Table 1-Properties of Soltrol-130 (Chevron-Phillips Chemical Company LP) \\
\hline Properties & Value \\
\hline Boiling Point & $181^{\circ} \mathrm{C}-209^{\circ} \mathrm{C}$ \\
\hline Specific Gravity & $0.762 @ 15.6^{\circ} \mathrm{C}(47 \mathrm{lb} / \mathrm{ft} 3)$ \\
\hline Viscosity & $1.55 \mathrm{cSt} @ 38^{\circ} \mathrm{C}$ \\
\hline Vapor Pressure & $1.5 \mathrm{mmHg} @ 38^{\circ} \mathrm{C}$ \\
\hline
\end{tabular}




\section{The experimental procedures (Core saturation and cyclic gas injection processes)}

1. The cores were dried prior to the saturation process. In order to know the weight of oil saturated into the shale cores, the dry weight of each core is required. Analysis of the microstructures in tight shales suggests that the organic porosity may play a dominant role for hydrocarbon accumulation and production (Handwerger, D.A. et al., 2012). The effect of nitrogen adsorption on the organic matter was not considered in simulation work. In this study, only oil and gas phases were considered in the displacement performance (no interstitial water). Since the pore size in tight shale formations is in the magnitude of microns in size, it is very difficult to saturate the oil in shale cores up to a desired oil saturation. To inject oil into tight shales, it is necessary to vacuum the cores using a vacuum pump to remove the air and create a high pressure difference between the injection line and shale cores. The cores were placed in the desiccators and vacuumed for 2 days.

2. The shale cores were saturated with Soltrol-130 oil at an injection pressure of 1000 psi for 24 hours.

3. Weigh all the cores again and record their saturated weight to calculate the oil saturation of the shale rocks.

$$
S_{o}=\frac{V_{o}}{V_{p}}=\frac{\left(W_{s a t}-W_{d r y}\right) / \rho_{o}}{V \varphi}
$$

4. After the saturation processes, the saturated shale cores were placed in a cylindrical core container. The N2 injection pump is opened to pressurize the system up to 1000 psi (shown in Fig.1). Fig.2 shows a schematic diagram of experimental set up for huff-n-puff tests (Yu and Sheng, 2015). The shale cores were exposed to the injected gas that allows the injected gas to penetrate into the shale matrix. The core container is placed in the oven which was heated to a constant temperature, $95^{\circ} \mathrm{F}$.

5. When the pressure showed on the pressure gauge reached to $1000 \mathrm{psi}$, shut down the injection pump. In order to allow injected gas to diffuse into oil phase in the shale matrix and to make the system reach equilibrium, the cores were soaked for 48 hours under a constant pressure (1000 psi). A uniform injection pressure in the system is maintained in the soak duration. Owing to the very low permeability nature of shale rocks, it requires a long time to be able to saturate the shale cores with oil to a desired level. We failed to saturate the shale cores up to a desired saturation level on the first a few attempts by using less than 24 hours, such as 2 hours, 4 hours and so on. Then, we decided to use 24 hours that allows sufficient time in the saturation process. Current experiments were performed at low pressures.

6. Once the soak period is finished, the pressure in the system is exposed to withdrawing down to the atmospheric pressure (14.7 psi). The pressure in the tight shale cores may drop at a slower rate than that in the cylinder. In the simulation model, the permeability of the fracture space between the core container and the shale cores is assumed to be much higher than the shale matrix. Pressure in the shale cores is required to be depleted to the atmospheric pressure before processing the next stage.

7. After the depletion process, the shale cores are weighed again to calculate the oil production during this gas huff-and-puff process.

8. Repeated above 4-7 steps at the same injection and soaking conditions for 8 cycles to observe oil recovery profile with increasing number of cycles. 


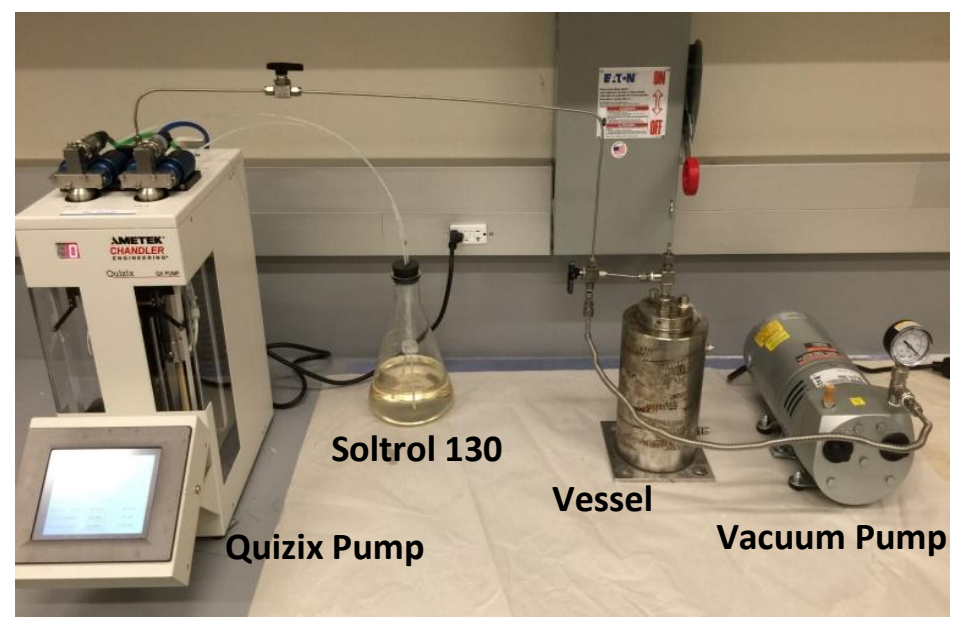

Fig.1. Experimental setup and apparatus

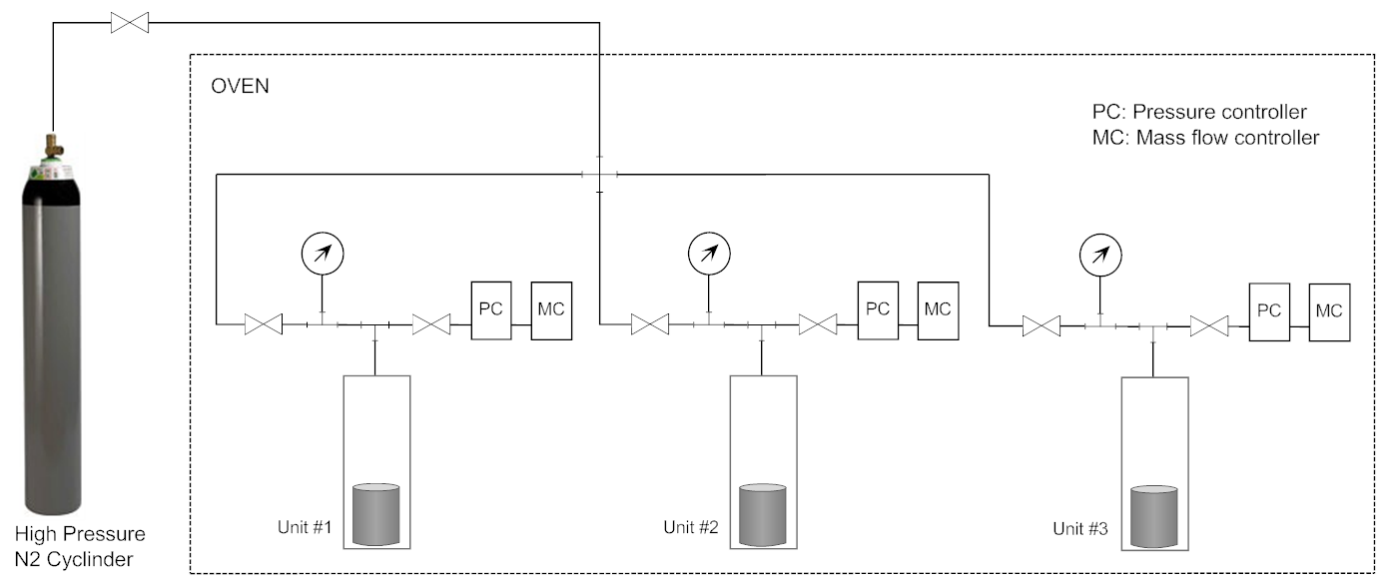

Fig.2. Schematic diagram of experimental set up used for huff-n-puff tests (Yu and Sheng, 2015)

\section{Simulation model description}

\begin{tabular}{|c|c|}
\hline \multicolumn{2}{|c|}{ Table 2- Properties of $\mathrm{C}_{15}$ at $95^{\circ} \mathrm{F}$} \\
\hline $\mathrm{C}_{15}$ at $95 \mathrm{~F}$ & Liquid \\
\hline Ideal Cp, BTU/lbmol-R & 75.82 \\
\hline Molecular weight, $\mathrm{g} / \mathrm{mol}$ & 206.00 \\
\hline Density, $\mathrm{lb} / \mathrm{ft} 3$ & 47.28 \\
\hline Phase volume, \% & 100.000 \\
\hline
\end{tabular}

We built a numerical simulation model whose validity was established by accurately simulating the cyclic gas injection results performed in the laboratory. In our simulation model, $\mathrm{C}_{15}$ is used to represent the mineral Soltrol130 oil. One reason is that the physical properties of the mineral oil are known. There is no solution gas in mineral oil. Multi-component composition and corresponding physical properties data of crude oils are needed as input to simulations. It is quite expensive to make measurements of sets of such data. The use of mineral oil will avoid experimental testing the oil chemical composition properties and reduce uncertainty in designing the huff-n-puff process. Chevron-Phillips chemical company stated that the Soltrol-130 solvent is a complex mixture of many 
different isoparaffinic molecules. Soltrol-130 isoparaffin solvent has the carbon number distribution in the $\mathrm{C}_{11}{ }^{-} \mathrm{C}_{15}$ range. Based on the given product properties, $\mathrm{C}_{15}$ that has similar properties (density and viscosity) as mineral oil is used to simulate the experiments. Although other critical properties have not been analyzed in detail yet, at this point we simply use $\mathrm{C}_{15}$ to represent the oil properties. Table 2 shows the properties of $\mathrm{C}_{15}$ at $95{ }^{\circ} \mathrm{F}$.

\begin{tabular}{|lcc|}
\hline \multicolumn{3}{|c|}{ Table 3- Reservoir and fluid properties used in this study } \\
Parameters & Value & Unit \\
Initial core pressure & 15 & $\mathrm{Psi}$ \\
Soaking pressure & 1000 & $\mathrm{Psi}$ \\
Reservoir temperature & 95 & ${ }^{\circ} \mathrm{F}$ \\
Porosity of shale matrix & $5 \%$ & $\mathrm{Fraction}^{-1}$ \\
Compressibility of shale & $5^{*} 10^{-6}$ & $\mathrm{psi}^{-1}$ \\
Shale matrix permeability & 0.0005 & $\mathrm{mD}$ \\
Fracture permeability & 1000 & $\mathrm{mD}$ \\
Oil density & 47.3 & $\mathrm{lb} / \mathrm{ft} 3$ \\
\hline
\end{tabular}

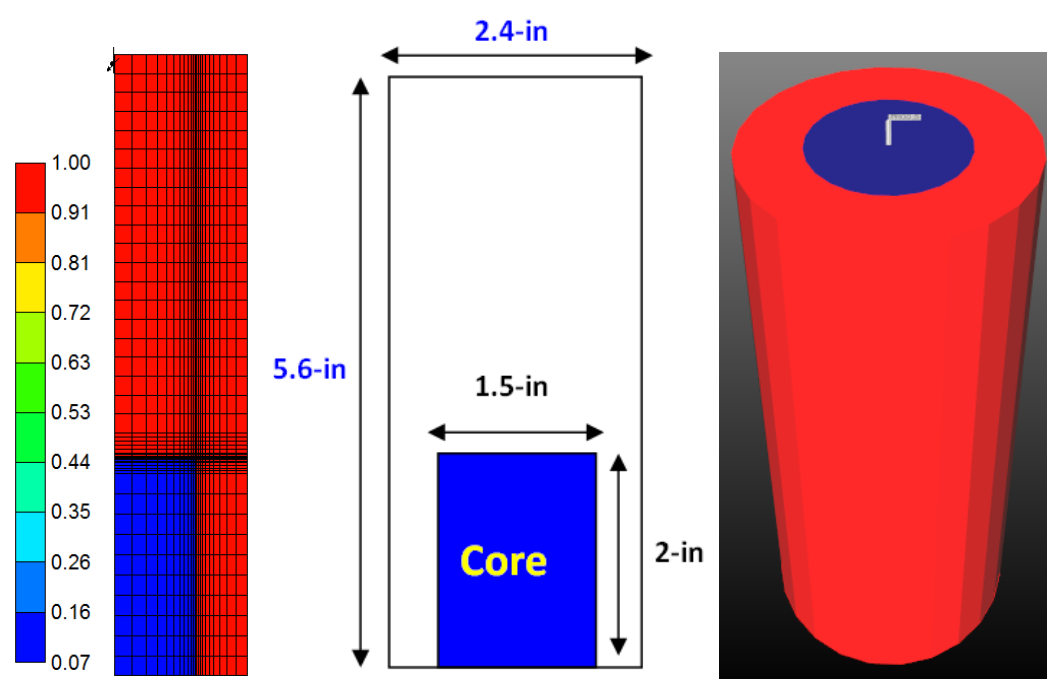

Fig.3. 2-D and 3-D reservoir simulation model (In 2-D model, blue area represents the shale core and the red area represents fracture) 


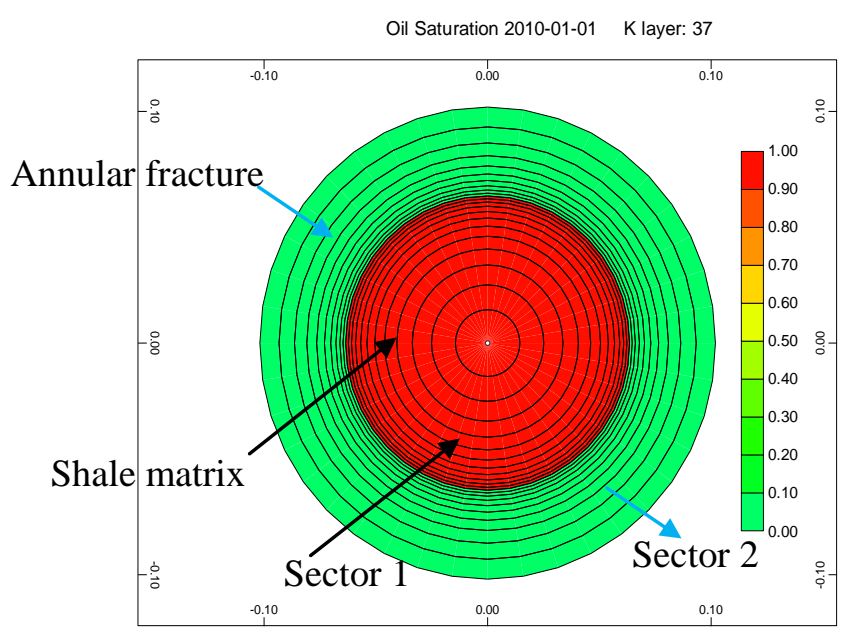

Fig.4. Base simulation model

We used a radial coordinate model and Computer Modeling Group (CMG-GEM) reservoir simulator to simulate the cyclic gas injection process in shale cores. Fig. 3 shows a 2-D IJ cross and 3-D view of reservoir simulation model. In this experiment, the shale core acting as a matrix block was centralized inside the vessel which is surrounded by the fractures. Gas is injected through the fracture and produced through fracture as well in the huff-n-puff process. The simulation model used the same dimension size as the physical experiment. The height of the core holder is approximately two times higher than the cylindrical shale sample. The dimension of the core holder (a diameter of 2.4-inch and 5.6-inch in height) is designed with a larger diameter and height than the shale cores, because the fracture was represented by the surrounding annular volume. All the faces of the shale sample are open during gas injection, diffusion and production stages. The permeabilities in the annular fracture space between the shale core and inside core container are set as $1000 \mathrm{mD}$. The Eagle Ford shale matrix permeability is assumed to be $0.0005 \mathrm{mD}$. In order to history match the experimental data, the model input parameters including fracture permeability, shale matrix permeability, relative permeability and diffusivity of oil and gas phases are tuned within an acceptable range. A two-dimensional radial cross section (x-z) was used to form the simulation domain. Table 3 shows us the reservoir rock and fluid properties in the simulation model. The simulation model has 46 layers with the highest permeability layer at the top (fracture permeability $=1000 \mathrm{mD}$ ). The shale matrix that has the lowest permeability is located at the bottom. A variable gridblock size ranges from 0.048 to 0.072 inch was used in the $\mathrm{x}$ direction and with refined gridblocks located near the fracture. The simulation domain is separated into two sectors in order to control the output of reservoir data on a regional basis. The shale cores are set as sector 1 and the fracture region is set as sector 2. The production well and injection well are located at gridblock $(1,1,1)$ at the top of sector 2 . It is important to notice that the actual volumes of oil and gas produced by wells are different from the oil and gas recoveries from sector 1 . Once the production well was shut down, there were no oil and gas recoveries from the well. However, oil and gas production from sector 1 is still possible because pressure drawdown in the shale cores may be slower than the fracture space which results in oil being driven out of the sector 1 by pressure gradients. Thus, the oil and gas recoveries by wells are different from the recoveries in sector 1 . The injection well is constraint to inject at a maximum injection pressure at $1000 \mathrm{psi}$ and a maximum surface gas rate at $1.2 \mathrm{MSCF} / \mathrm{D}$. The injector will automatically change its mode of control whenever the existing control mode would violate one of these limits. The production well is subject to minimum bottom-hole pressure at $14.7 \mathrm{psi}$. This allows us to conveniently implement the displacement process of the cyclic gas injection in laboratory. Once we open the injection valve, pressure in the annular fracture will reach to $1000 \mathrm{psi}$ within 1-2 minutes. However, it requires some time for the gas in the fracture space to diffuse into tight shale matrix and achieve pressure and concentration equilibriums.

\section{Results and Discussion}


Fig. 5 shows oil production response from 1th-5th cycle in the course of cyclic gas injection. Cyclic gas injection was quite effective, especially in the first few cycles. Subsequent cycles of $\mathrm{N}_{2}$ injection recovered additional incremental oil with some decline in process efficiency. Table $\mathbf{4}$ and $\mathbf{5}$ investigated the effect of depletion time on ultimate oil recovery. These two group comparison experiments probe the relationship between the rate of withdrawal and recovery performance of shale reservoirs. Table 4 and 5 presented shale oil recovery results with $0.05-\mathrm{hr}$ and $40-\mathrm{hr}$ of depletion time, respectively. The core pressure was systematically decreased to 15 psi over depletion time. The depletion time refers to the time required for the initial fracture pressure declined to atmospheric pressure in a huff-n-puff cycle. Fig. 6 shows the comparison of shale oil recovery performance during 8 cycles of gas injection process using two different withdrawal rates. The experimental results presented in Fig. 6 showed that more oil recovery will be obtained with increased withdrawal rates.

\begin{tabular}{|l|c|c|c|c|c|c|c|c|}
\hline \multicolumn{8}{|c|}{ Table 4- Measured shale oil recovery factor and oil saturation with a deletion time of 0.05-hr } \\
\hline Number of cycles & 1 & 2 & 3 & 4 & 5 & 6 & 7 & 8 \\
\hline Cumulative R.F. & $14.23 \%$ & $21.37 \%$ & $26.47 \%$ & $31.50 \%$ & $35.72 \%$ & $39.51 \%$ & $42.79 \%$ & $45.45 \%$ \\
\hline Oil Saturation & 0.86 & 0.79 & 0.74 & 0.68 & 0.64 & 0.60 & 0.57 & 0.55 \\
\hline
\end{tabular}

\begin{tabular}{|l|c|c|c|c|c|c|c|c|}
\hline \multicolumn{8}{|c|}{ Table 5-Measured recovery factor and oil saturation with a deletion time of 40-hr } \\
\hline Number of cycles & 1 & 2 & 3 & 4 & 5 & 6 & 7 & 8 \\
\hline Cumulative R.F. & $11.41 \%$ & $16.95 \%$ & $21.65 \%$ & $25.82 \%$ & $29.36 \%$ & $32.62 \%$ & $36.15 \%$ & $39.66 \%$ \\
\hline Oil Saturation & 0.88 & 0.83 & 0.78 & 0.74 & 0.71 & 0.67 & 0.64 & 0.60 \\
\hline
\end{tabular}
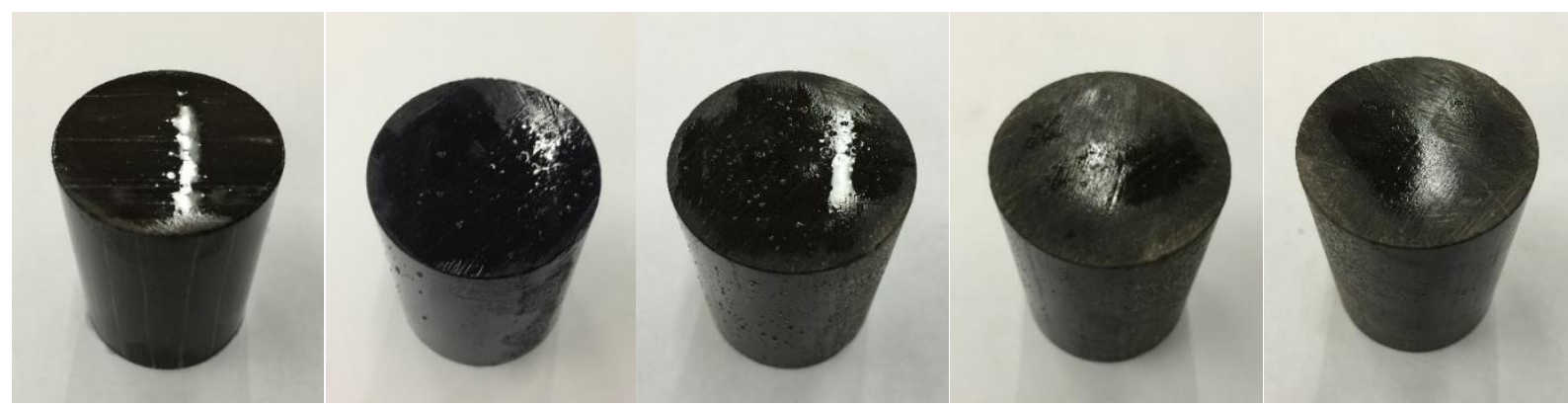

Fig.5. Shale oil production response in cyclic gas injection processes from 1th-5th cycle

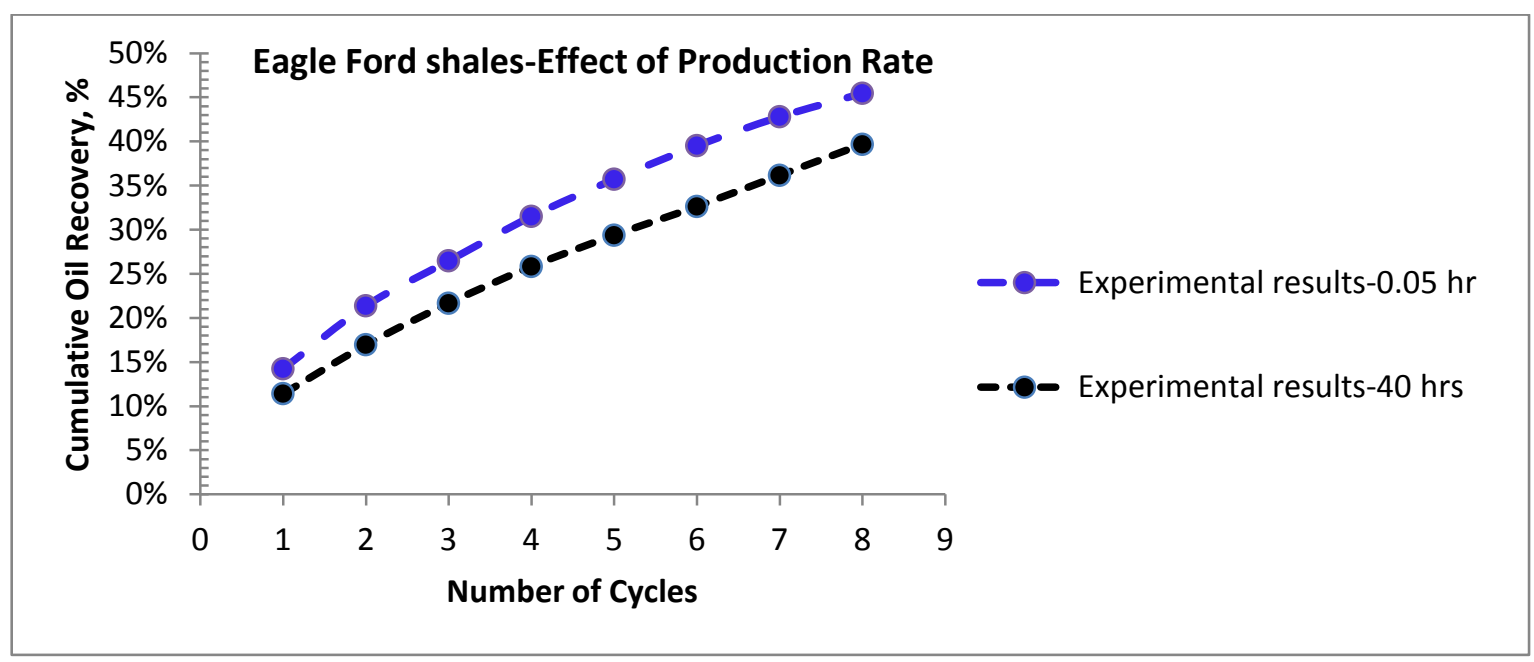


Fig.6. Effect of depletion time on CGI recovery performance

The effect of producing rate on ultimate oil recovery has been studied by many researchers. Results from conventional reservoirs demonstrated an increased ultimate recovery was yielded at high producing rates purely from the perspectives of reservoir flow mechanics (Beveridge, 1974; Permyakov and Gadok, 1961). Previous studies (Morel et al.1993) showed that capillary end effect comes into play in lab-scale coreflooding, with an accumulation of liquid near the fracture that delays liquid production. With a fast withdrawal rate, the capillary end effect is significantly reduced. However, other investigations showed that high production rates might lead to a reduction in the ultimate recovery compared to that with a slow withdrawal rate (Miller et al. 1949). Longer producing time periods will assist in recovering oil more effectively by the mechanisms of gravity drainage and cross-current. The recovery is affected by so many parameters that the variations in recovery are not constrained to any one factor such as rates.

The water, oil and gas relative permeability data are obtained from a previous Bakken reservoir simulation study (Shoaib and Hoffman, 2009), as shown in Fig.7. It is difficult to get the measured relative permeability curves in lab. Straight-line relative permeabilities are used for fractures.
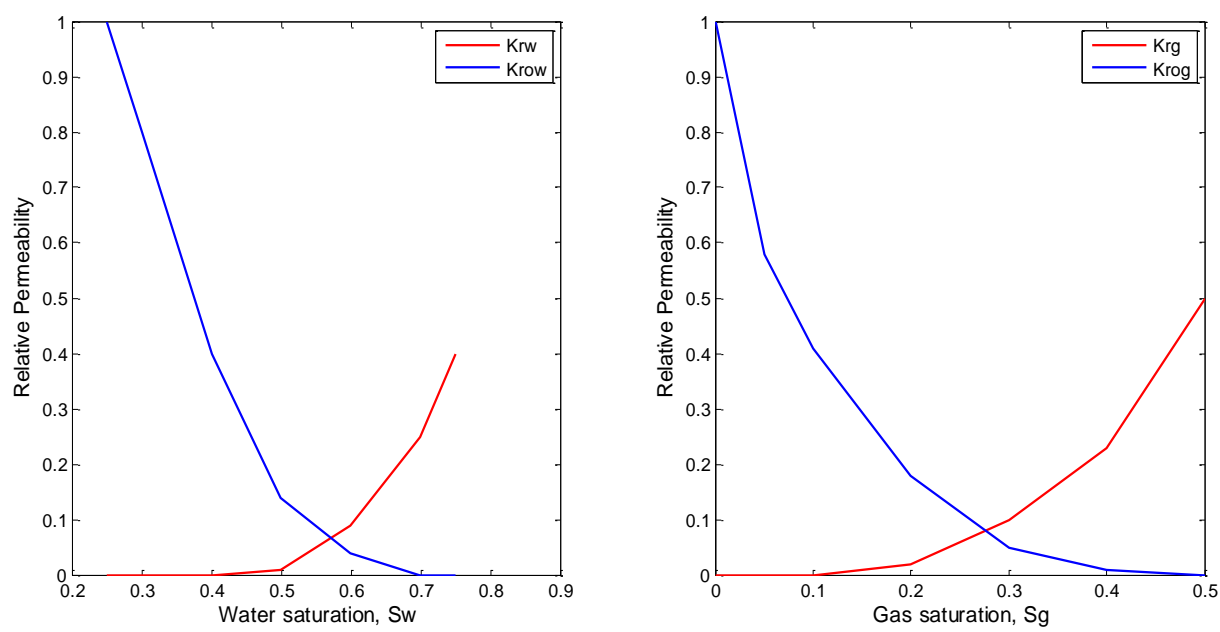

Fig.7. Relative permeability curves used in the simulation model (Shoaib and Hoffman, 2009)

In this simulation study, we examined the impact of grid refinement on the recovery performance by performing a series of numerical sensitivity calculations. Fig.8 illustrates that using $22 \times 1 \times 46$ 2D gridblocks is producing similar results as more refined 50x1x46 gridblocks. Grid refinement near the transition zone between highly conductive fracture and shale matrix is needed to produce steady numerical solutions. Fig. 8 shows that a $22 \times 1 \times 46$ gridblock model is able to properly simulate the gas injection processes. There are some unknown parameters in this simulation model such as annular fracture permeability, relative permeability curves and shale matrix permeability. The simulation model that obtains a good agreement with the laboratory data is not unique since simulation output results are affected by these unknown input parameters. Fig.9 investigated the effect of fracture permeability on enhanced oil recovery performance. It is seen from Fig. 9 that annular space permeability does not affect the cumulative oil recovery significantly provided that it is larger than $1000 \mathrm{mD}$. 


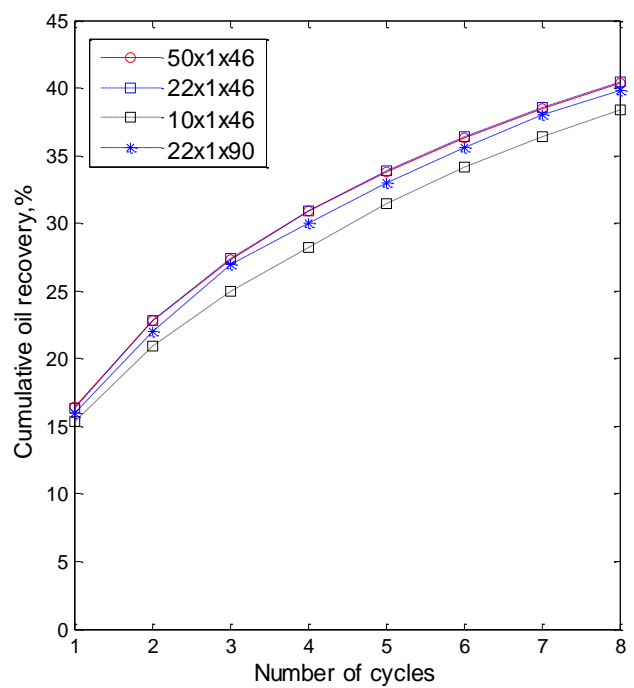

Fig.8. Effect of grid block size on calculated oil R.F.

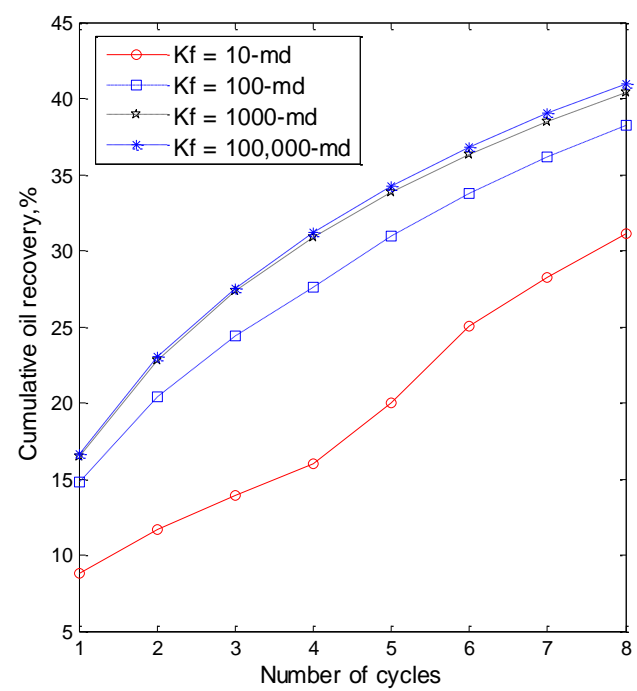

Fig.9. Effect of fracture permeability on cyclic gas injection performance

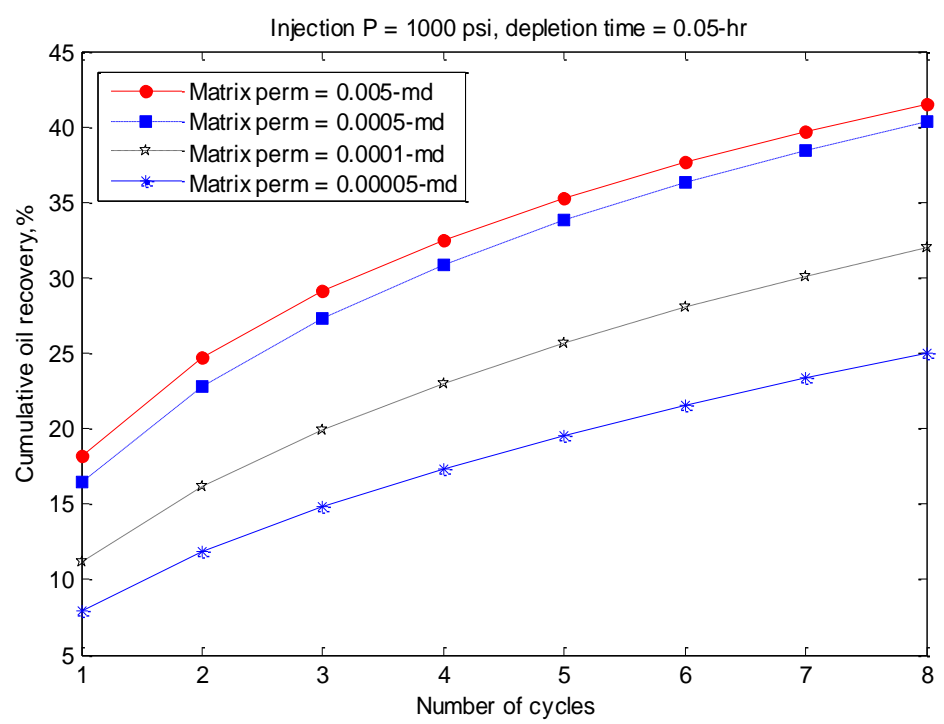

Fig.10. Effect of shale matrix permeability on cumulative oil recovery 


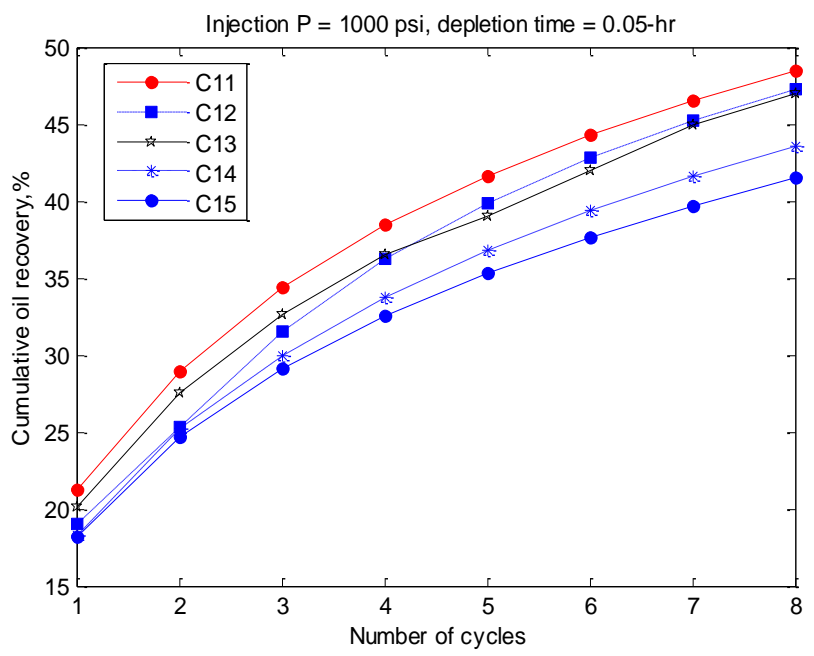

Fig.11. Effect of fluid composition on cumulative oil recovery

The fracture permeability ranges from $100-100,000 \mathrm{md}$ in the history matching process. The shale matrix permeability is from 0.00005-0.005 md. The effective diffusion coefficients for each component of the mixture could be estimated by Wilke-Chang approach (Wilke and Chang, 1955). Since we are lack of the apparatus to measure the shale permeability, the intent of Fig.10 is to show the effect of shale matrix permeability on the performance of cyclic gas injection. In the base simulation model, the fracture permeability is $1,000 \mathrm{md}$ that gives a good history matching with the experimental data. The shale matrix permeability is $0.0005 \mathrm{md}$. The shale matrix porosity is $7 \%$. This porosity value is determined from the lab measurement, which is not subject to change in the tuning process. The tuning process is a trial-and-error process. Once we attained a good history match with the experimental data, the base model remains unchanged. We change only one variable at a time at the sensitivity studies. Fig. 11 shows the sensitivity study of the effect of fluid composition on cumulative oil recovery in cyclic gas injection process. The simulation results indicate that the cumulative oil recovery was affected by the reservoir fluid composition. Suppose lighter oil compositions were used, the recovery profile trend suggests that higher oil recovery would be expected.

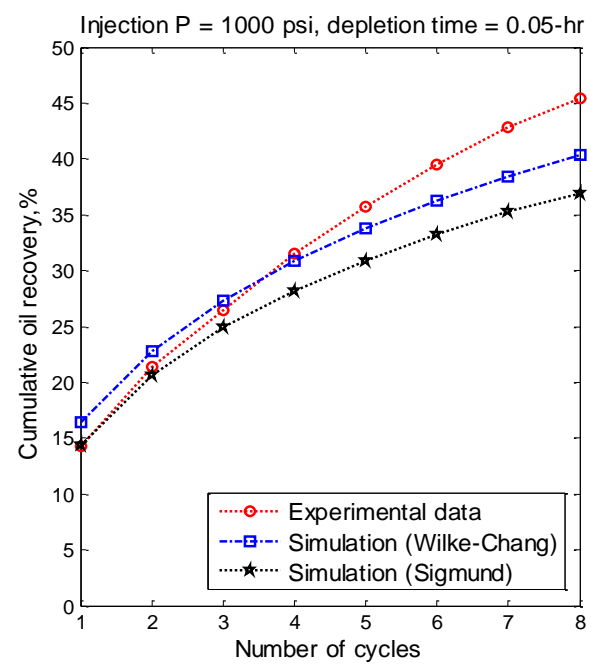

Fig.12. Comparison of simulation results with experimental data ( 0.05 hours)

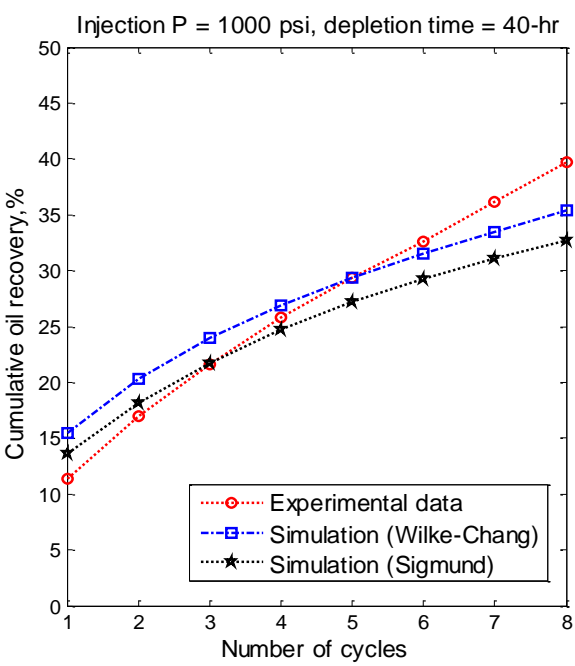

Fig.13. Comparison of simulation results and experimental data (40 hours) 
Note that in the current simulator we used, it is assume conventional flow equations like Darcy equation are valid. More importantly, it is assumed that relative permeability curves and capillary pressure curves follow typical curves for the flow in conventional reservoirs. Laboratory measurements for these curves are needed. However, how to obtain those curves is a challenge. Also, further studies are needed to better understand the mechanisms of oil recovery in shale oil reservoirs by cyclic gas injection.

The diffusion mechanism is considered in computing the matrix and fracture molecular fluxes. The dispersiveconvective flux through nanopores in shale oil reservoirs is modeled during gas injection process. Fig. 12 shows the comparison of simulation results with the experimental data at 1000 psi injection pressure with 0.05 hrs of depletion time. The molecular diffusion coefficients could be calculated by Sigmund (1976) method. The diffusion coefficient correlation expressed by Sigmund method is:

$$
\begin{gathered}
\frac{\rho D}{\rho^{0} D^{0}}=0.99589+0.096016 \rho_{r}-0.22035 \rho_{r}^{2}+0.032874 \rho_{r}^{3} \\
\rho_{r}=\frac{\rho}{\rho_{c}}
\end{gathered}
$$

The effective diffusion coefficients for each component of the mixture could also be estimated by Wilke-Chang approach. The Wilke-Chang molecular diffusion coefficient correlation is described by these formulae:

$$
\begin{aligned}
& D=\frac{7.4 \times 10^{-8}(x M)^{0.5} T}{\mu V^{0.6}} \\
& x M=\frac{\sum_{j \neq 1} y_{i} M_{i}}{1-y_{i}}
\end{aligned}
$$

Based on the above equation, the typical values used in the model are $1.43 \mathrm{E}-06 \mathrm{~cm}^{2} / \mathrm{s}$ for the oil phase diffusion and $1.12 \mathrm{E}-04 \mathrm{~cm}^{2} / \mathrm{s}$ for gas phase diffusion.

Fig. 13 shows the oil recovery produced by Wilke-Chang correlation is closer to the experimental data than using Sigmund's correlation. In Fig. 13, the history matching results of the measured cumulative oil recovery in eight cycles with 40 hours of depletion time is history-matched. There is a slight deviation between the experimentally measured data and simulation results. This is primarily due to the fact that the micro-fractures are not considered in the simulation model, while natural fractures might exist in the shale cores that result in a higher oil recovery. Fig. $\mathbf{1 4}$ shows a good agreement between the measured oil saturations and calculated oil saturations by simulation. 


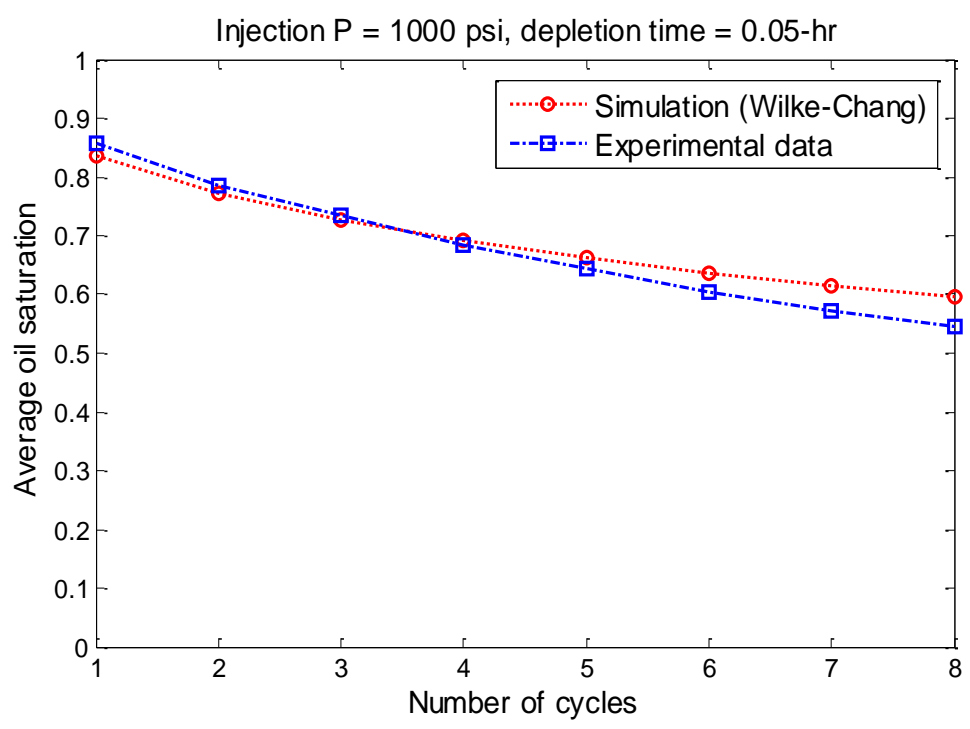

Fig.14. Comparison of simulated oil saturation and measured data

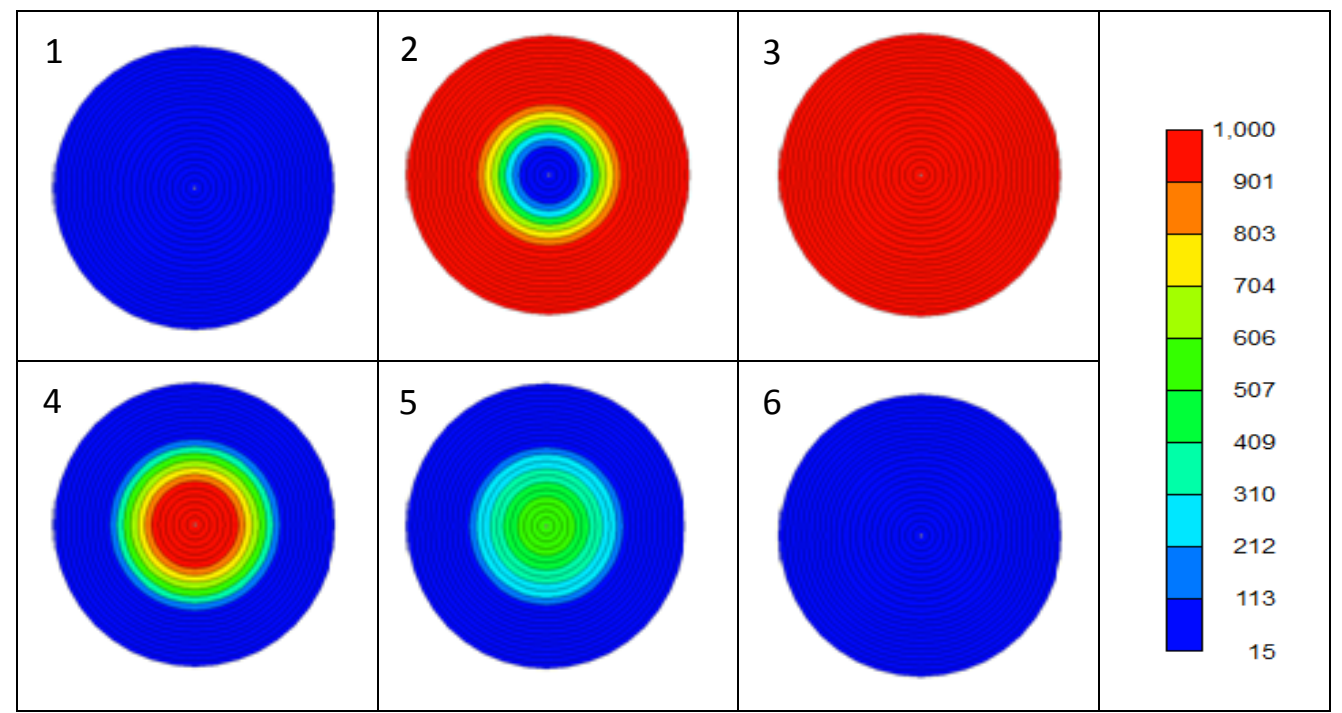

Fig.15. Pressure variations in one cycle of huff-n-puff process

\begin{tabular}{|c|c|c|c|c|}
\hline \multicolumn{5}{|c|}{ Table 6-Operational schedules in a cycle } \\
\hline Time (days) & $0-0.001$ & $0.001-2$ & $2-3.67(40 \mathrm{hrs})$ & $3.67-4$ \\
\hline Operations & Injector open & Soak & Producer open & Further depletion \\
\hline
\end{tabular}

Table 6 shows the operational schedule in a huff-n-puff cycle. Fig.15 displays the reservoir pressure variations during the nitrogen huff-n-puff processes at time 0, 0.001 days injection, 2 (soaking), 2.1 (after 0.1-day of production), 3 (after 1 day of production) and time 4 (depleted to atmospheric pressure), respectively. The first figure represents the initial pressure distribution (15 psi) of the system. The second figure shows the pressure distribution after 0.001-day of gas injection. It is observed that the pressure buildup in the fracture space is much faster than that in the shale cores. When pressure in the fracture was increased to $1000 \mathrm{psi}$, the pressure in the inner shale cores still remained around $15 \mathrm{psi}$. The injected nitrogen front slowly propagates through the shale matrix. The region beyond the gas invaded region remains at initial reservoir pressure. As time progresses, nitrogen penetrates deep along the radial direction into the shale matrix with a progressive increase in the size of the treated shale zone. 
The soak period is designed to allow the injected gas in the fracture to diffuse into the shale matrix to achieve compositional and pressure equilibriums. In regarding to how long it takes to attain an equilibrium state in the system, it depends on a lot of factors, such as fracture permeability, shale cores permeability and fluids properties (diffusive velocity). The third figure shows the pressure distribution after the system achieves equilibrium (1000-psi). During the gas production phase, the pressure drawdown in the fracture spacing decreases at a higher rate than the tight shale cores. The fourth figure shows the pressure distribution after 0.1-day of production. The pressure in the fracture declines to the minimum allowable bottom-hole flowing pressure ( $15 \mathrm{psi})$ in a short period of time, while the pressure in the inner gridblocks of shale cores remained 1000 psi. The fifth figure shows the pressure distribution after 1 day of production. The sixth figure shows pressure distribution when the whole system is depleted to atmospheric pressure (15-psi). In the production cycle, the average pressure in the fracture is lower than the shale matrix, which results in oil and nitrogen being displaced out by pressure difference. Owing to the high oil concentration and high pressure resided in the shale matrix, the transport mechanisms of oil component are a combination of diffusive and viscous displacement.

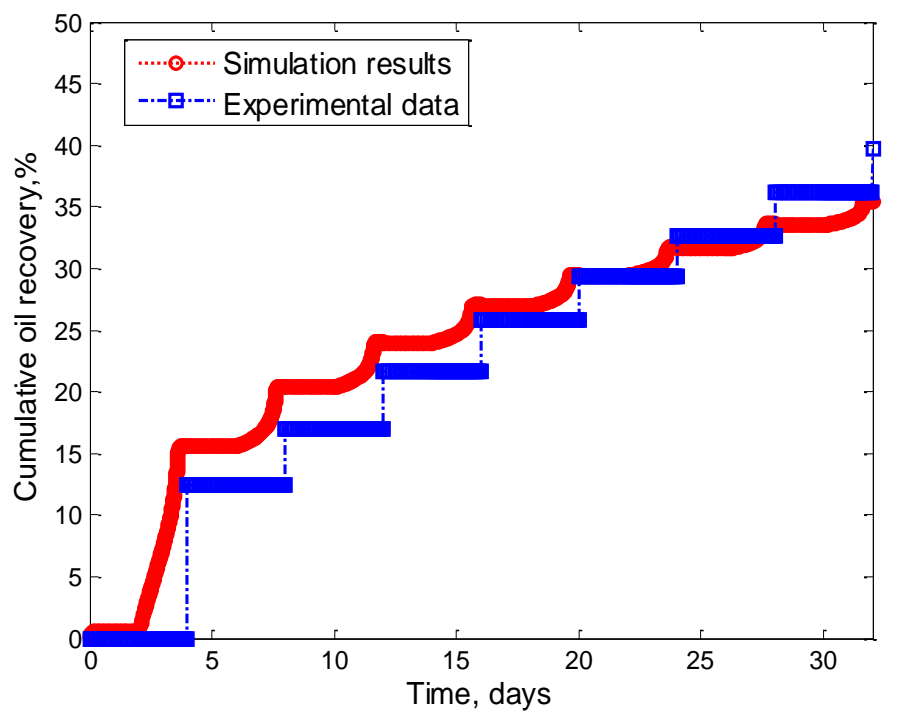

Fig.16. Comparison of simulation results and experimental data $(\mathrm{Pi}=1000 \mathrm{psi}$, depletion time $=40-\mathrm{hr})$

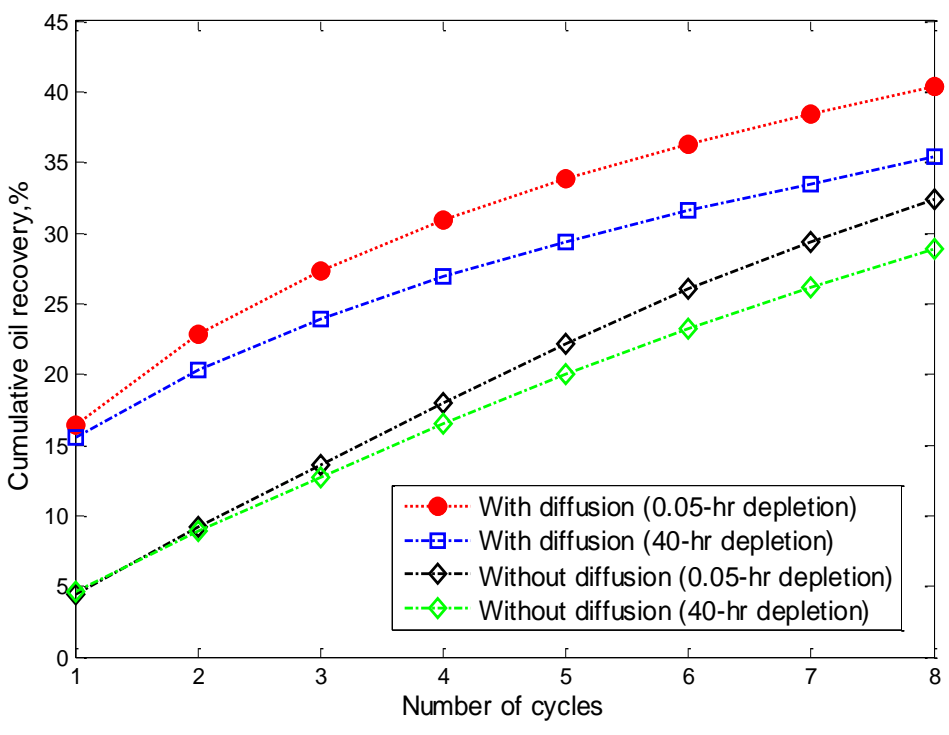

Fig.17. Effect of diffusion on ultimate oil recovery 
Fig.16 shows comparisons between the simulation model output results and experimental results based on time scale. Due to the fact that we only measured oil recovery at the end of each cycle, the oil recovery was increased instantaneously and sharply for experimental data. Although there is some deviation at the first few cycles between simulation results that include molecular diffusion model with the experimental results, they are in good agreement at subsequent cycles. It is recognized that oil is continuously produced until the pressure in the shale matrix is in equilibrium with the fracture, which is clearly presented in the Fig.16. After having been subjected to multiple cycles of nitrogen injection, the oil recovery from the treated shale cores increased substantially. The importance of diffusion effect is observed in Fig.17. It is noteworthy that the impact of diffusion is more significant than the production time on ultimate oil recovery. With diffusion included in the simulation model, the results exhibited roughly $10 \%$ higher oil recovery. Without considering the diffusion effect, the principle drive mechanism is viscous displacement. In absence of diffusion, the incremental oil recoveries at each cycle are increasing at roughly equal rates because applied pressure differentials in each cycle are the same. Simulation results showed that withdrawing the nitrogen in the annual fracture space at rapid rates produced a higher cumulative oil recovery than slow rates, which is consistent with the experimental observations showed in Fig.6.

Earlier studies on cyclic gas injection suggest that oil swelling, oil viscosity reduction and gas relative-permeability hysteresis are the principle driving mechanisms (Thomas and Monger, 1991). Abboud (2005) studied the effect of the cyclic injection of $\mathrm{N}_{2}$ and $\mathrm{N}_{2} / \mathrm{O}_{2}$ mixtures on the reservoir fluid compositional changes due to vaporization process. Their laboratory PVT tests showed that light hydrocarbons had more of a tendency to be vaporized than heavy components. Farias and Watson (2007) experimentally investigated the impacts of injected gas solubility and oil vaporization on the cyclic gas injection process. Different quality mixtures of $\mathrm{CO}_{2}$ and $\mathrm{N}_{2}$ were used to examine the interaction of injection gases with crude oil. Laboratory results showed that gas solubility is higher at the first 3 to 4 cycles than later cycles. Another observation they made is that $\mathrm{CO}_{2}$ has a preference to vaporize the heavier components while $\mathrm{N}_{2}$ tends to extract light and medium hydrocarbon components. The difference of the composition between the recovered gas and the injected gas was used to support these conclusions. In this paper, we focus on discussing the mechanism of diffusion (soak duration) on cyclic response because of the unique characteristic of shales, exceptionally low matrix permeability.

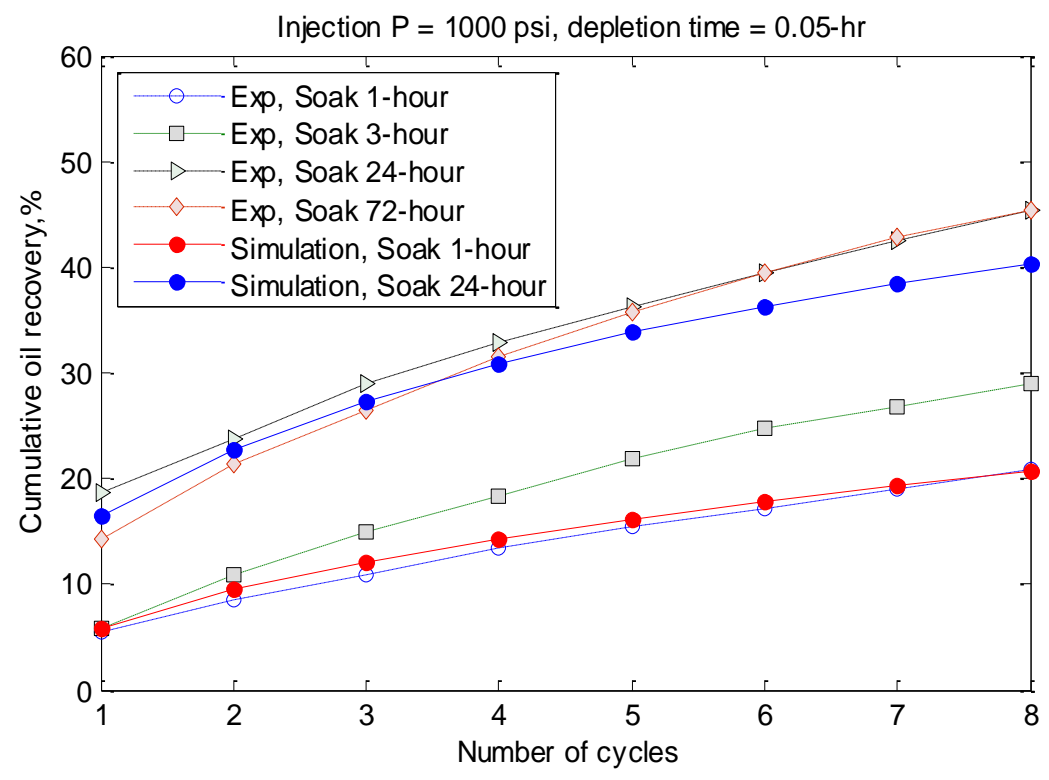

Fig.18. Effect of soak duration on production response

The effect of soak duration on ultimate oil response remains controversial. Monger and Coma (1988) pointed out that the cyclic process response was not sensitive to the soak duration in huff-n-puff field tests. However, Thomas and Monger (1991) showed that incremental oil recovery increased by extending the soak periods up to 4 weeks, 
provided that incremental oil not discounted for production lost during soak periods. Recent experimental observations reported by $\mathrm{Yu}$ and Sheng (2015) furthered investigation of the effect of soak duration on process response in Eagle-Ford shale reservoirs by cyclic nitrogen injection (Fig.18). Based on their experimental data, we used a numerical simulation approach to enhance our understanding of cyclic gas recovery mechanisms. Fig.18 shows that a 24-hour of soak time results in a more favorable oil recovery profile than 1-hour of soak time. However, extending the soak length from 24-hour to 72-hour has immaterial effect on the production response improvement. Production losses during the soak periods can be reduced by employing the optimal cycle length. The comparison conducted between 24-hour and 72-hour soak showed that production response is less efficient by the long soak duration. It was speculated that experimental errors existed in the measurements of the 24-hour and 72-hour soaks.
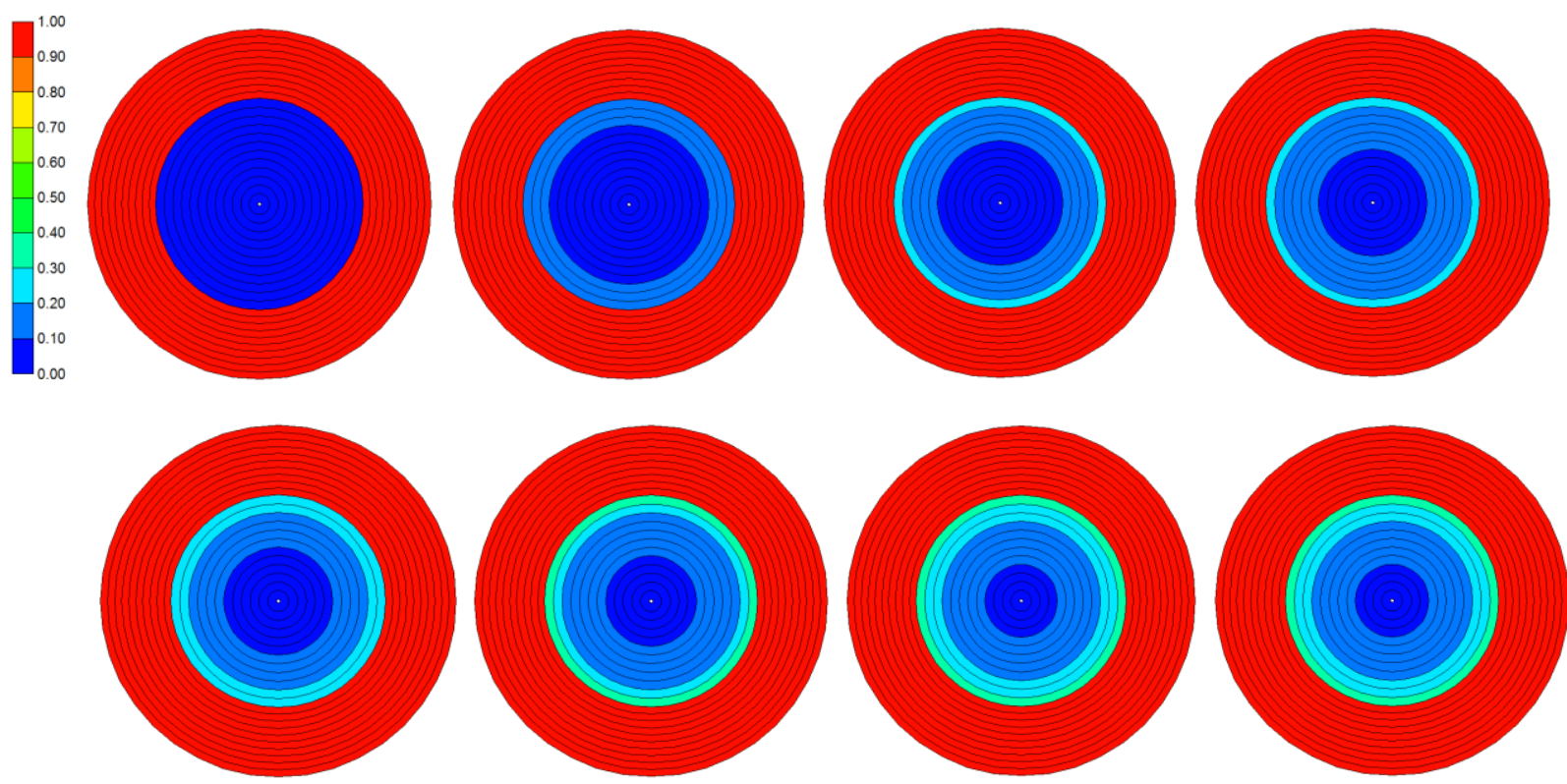

Fig.19. $\mathrm{N}_{2}$ mole fraction in the shale matrix from $1^{\text {th }}-8^{\text {th }}$ cycle (1-hour soak time)

The effect of soak periods during cyclic gas injection process in nano-permeable shales is presented in Fig.18. The importance of diffusion is described by the relation between process performance and soak duration. A soak period is dominated by diffusive transport of injected nitrogen in the fracture to the shale matrix. A soak period allows free gas to contact with oil that is not near the core inlet. The $\mathrm{N}_{2}$ mole fraction in the shale matrix from $1^{\text {th }}-8^{\text {th }}$ cycle is shown in Fig.19. Nitrogen dissolved in the oil phase is increasing progressively as the cycles proliferate. In the cases of cyclic $\mathrm{CO}_{2}$ injection, laboratory core-flooding results by Monger and Coma (1988) suggested that hydrocarbon extraction into $\mathrm{CO}_{2}$ rich phase also requires a soak period. Detailed discussion about the role of diffusion in a fieldscale gas flooding in fractured shale oil reservoirs is referred to Wan and Sheng (2015). It is recognized that diffusion effect is an important recovery mechanism in mobilizing and recovering oil from nanopore systems.

The prediction performance of cyclic gas injection at the core scale is different from the reservoir scale. More efforts needed to be made on how to relate or upscale the core-scale observations to field-scale behavior. The feasibility of gas huff-n-puff to enhanced oil recovery in Bakken fields was examined by Kurtoglu (2013). Simulation results indicated that well spacing and fracture density are the key factors that dictate the well productivity in EOR process. In the laboratory design (Fig.3), the shale matrix is extensively exposed to the fractures, which is not likely to happen in a large field-scale flooding. The exposure of nano-Darcy permeability shale rock to the injected gas in the experiments is greater than a field case. The experimental results are inevitably better than field production performance in shale reservoirs.

\section{Conclusions}


This study focused on evaluating the potential of oil recovery by cyclic nitrogen injection in shale oil reservoirs. Our understanding about huff-n-puff in shale plays can be furthered by comparing model predictions with experimental observations. The effects of pressure depletion rate, soak duration and diffusion on process performance were discussed. Further studies are needed to better understand the mechanisms of oil recovery in shale oil reservoirs by cyclic gas injection.

1. The applicability of cyclic gas injection to recover oil in liquid-rich shales has been investigated by both experimental data and numerical simulation.

2. The first cycle yielded highest oil recovery by immiscible cyclic nitrogen injection in liquid-rich shales. Additional oil produced from subsequent cycles is significantly decreased compared to previous cycles. As it is seen in Fig. 6, the first cycle recovered 14\% oil recovery, the second cycle recovered additional $7 \%$ and the third cycle recovered 5\%. With the increase number of gas injection cycles, the incremental oil recovery is declined.

3. Results of the simulation and experiments showed that higher ultimate recovery was yielded at higher producing rates.

4. The simulation model that includes the molecular diffusion recovery mechanism exhibits higher oil recovery response than without it. The diffusion effect should be considered in recovering oil from nanopermeable shale rocks by secondary cyclic injection method.

5. It requires some time for the gas in the fracture space to diffuse into the oil phase in tight shale cores and achieve pressure and concentration equilibriums with the shale cores. .

\section{Acknowledgments}

The work presented in this paper is supported by the Department of Energy under Award Number DE-FE0024311 and ConocoPhillips Corporation. Their support is greatly appreciated.

\section{Nomenclatures}

$\mathrm{D}=$ diffusion coefficient, $\mathrm{cm}^{2} / \mathrm{sec}$

$\mathrm{S}_{\mathrm{o}}=$ oil saturation

$\mathrm{T}=$ temperature, ${ }^{\circ} \mathrm{K}$

$\mathrm{x}=$ association parameter, multiple of nominal molecular weight of solvent

$\mathrm{V}=$ molar volume of solute at normal boiling point, cc/g.mole

$\mathrm{V}_{\mathrm{o}}=$ oil volume

$\mathrm{V}_{\mathrm{p}}=$ pore volume

$\mathrm{W}_{\text {sat }}=$ weight of core sample saturated with oil

$\mathrm{W}_{\mathrm{dry}}=$ weight of dry core sample

$y=$ mole fraction

$\rho_{o}=$ oil density

$\varphi=$ porosity

$\mu=$ viscosity of solution, $\mathrm{cp}$ 
$\rho^{0} D^{0}=$ zero pressure limit of the density-diffusivity product

$\rho_{c}=$ molar critical density

$\rho_{r}=$ reduced density

$\rho=$ molar density of the diffusing mixture

Subscripts

$\mathrm{r}=$ reduced

$\mathrm{c}=$ critical

\section{References:}

1. Abboud, A. 2005. A Study of Cyclic Injection of Nitrogen on Mid-Continent Crude Oil: An Investigation of the Vaporization Process in Low Pressured Shallow Reservoirs. Master's thesis, The Pennsylvania State University, University Park, Pennsylvania.

2. Beveridge, S.B., Coats, K.H., Agrawal, R.K. and Modine, A.D., 1974. A Study of the Sensitivity of Oil Recovery to Production Rate. SPE 5129, Fall Meeting of the Society of Petroleum Engineers of AIME, 6-9 October, Houston, Texas.

3. Black, D.J., Aziz, N.I., Ren, T.X., 2011. Enhanced Gas Drainage from Undersaturated Coalbed Methane Reservoirs. No.50, The $3^{\text {rd }}$ Asia Pacific Coalbed Methane Symposium, May 3-6, Brisbane, Australia.

4. Chen, C., Balhoff, B., Mohanty, K. K., 2014. Effect of Reservoir Heterogeneity on Primary Recovery and CO2 Huff-n-Puff Recovery in Shale-Oil Reservoirs. SPEREE 17 (03), 404-413. Doi: 10.2118/164553-MS.

5. Farias, M.J., and Watson, R. W. 2007. Interaction of Nitrogen/CO2 Mixtures with Crude Oil, Final Report. Pennsylvania State University, University Park, PA, USA.

6. Gamadi, T.D., Sheng, J.J., Soliman, M.Y., 2013. An Experimental Study of Cyclic Gas Injection to Improve Shale Oil Recovery. SPE 166334, SPE Annual Technical Conference and Exhibition held in New Orleans, Louisiana, USA, 30 September-2 October.

7. Handwerger, D.A., Suarez-Rivera, R., Vaughn, K.I., Keller, J.F., 2012. Methods Improve Shale Core Analysis. The American Oil and Gas Reporter.

8. Javadpour, F., Fisher, D., and Unsworth, M., 2007. Nanoscale Gas Flow in Shale Gas Sediments. JCPT 46 (10), 55-61. Doi: 10.2118/ 10.2118/07-10-06.

9. Kovscek, A.R., Tang, G.Q., Vega, B., 2008. Experimental Investigation of Oil Recovery from Siliceous Shale by CO2 Injection. SPE 115679, SPE Annual Technical Conference and Exhibition held in Denver, Colorado, 19-22 September.

10. Kurtoglu, B., 2013. Integrated reservoir characterization and modeling in support of enhanced oil recovery for Bakken. Ph.D. dissertation at petroleum engineering at the Colorado School of Mines.

11. Lofton, L.K. and Morse, R.A., 1978. The Effects Of Injection Pressure On Condensing Gas Drive Recovery. SPE 7472, SPE Annual Fall Technical Conference and Exhibition, 1-3 October, Houston, Texas.

12. Miller, C. C., Brownscombe, E. R., \& Kieschnick Jr, W. F., 1949. A Calculation of the Effect of Production Rate upon Ultimate Recovery by Solution Gas Drive. JPT, 1(09), 235-247. DOI: http://dx.doi.org/10.2118/949235-G.

13. Monger, T.G., and Coma, J.M., 1988. A Laboratory and Field Evaluation of the CO2 Huff ' $n$ ' Puff Process for Light-Oil Recovery. SPE Reservoir Engineering, 3 (04), 1168-1176, SPE-15501-PA. DOI: http://dx.doi.org/10.2118/15501-PA.

14. Monger, T.G., Ramos, J.C., and Thomas, J., 1991. Light Oil Recovery from Cyclic CO2 Injection: Influence of Low Pressures, Impure CO2, and Reservoir Gas. SPE Reservoir Engineering, 01(6), 25-32. DOI: http://dx.doi.org/10.2118/18084-PA. 
15. Morel, D., Bourbiaux, B., Latil, M., Thiebot, B., 1993. Diffusion Effects in Gasflooded Light-Oil Fractured Reservoirs. SPE J. 1(02), 100-109. DOI: http://dx.doi.org/10.2118/20516-PA.

16. Ozkan, E., Raghavan, R.S., Apaydin, O.G., 2010. Modeling of Fluid Transfer From Shale Matrix to Fracture Network. SPE 134830, SPE Annual Technical Conference and Exhibition, 19-22 September, Florence, Italy.

17. Permyakov, I.G. and Gadok, N.S., 1961. The Desirability of Exploitation of Oil Fields at High Rates of Oil Production. Neftyanoe Khoz, 39 (6), 33-68.

18. Sakhaee-Pour, A. and Bryant, S., 2012. Gas Permeability of Shale. SPE J 15 (4), 401-409. SPE-146944-PA.

19. Shayegi,S., Jin, Z., Schenewerk, P., Wolcott, J., 1996. Improved Cyclic Stimulation Using Gas Mixtures. SPE 36687, SPE Annual Technical Conference and Exhibition, 6-9 October, Denver, Colorado.

20. Shoaib, S. and Hoffman, B.T. 2009. $\mathrm{CO}_{2}$ flooding the Elm Coulee Field. SPE 123176 paper was prepared for presentation at the 2009 SPE Rocky Mountain Petroleum Technology Conference held in Denver, Colorado, USA, April 14-16.

21. Sigmund, P.M., 1976. Prediction of Molecular Diffusion At Reservoir Conditions. Part 1- Measurement And Prediction of Binary Dense Gas Diffusion Coefficients. JCPT, 15 (2): 48-57. Doi: http://dx.doi.org/10.2118/76-02-05.

22. Wan, T., Sheng, J.J., Soliman, M.Y., 2013. Evaluate EOR Potential in Fractured Shale Oil Reservoirs by Cyclic Gas Injection. SPE 168880, Unconventional Resources Technology Conference held in Denver, Colorado, USA, 12-14 August.

23. Wan, T., and Sheng, J.J. 2015. Compositional Modeling of the Diffusion Effect on EOR Process in Fractured Shale Oil Reservoirs by Gas Flooding. Journal of Canadian of Petroleum Technology, 54 (02): 107-115. SPE-1891403-PA. DOI: http://dx.doi.org/10.2118/2014-1891403-PA.

24. Wang, Z., Ma, J., Gao, R., Zeng, F., Huang, C., Tontiwachwuthikul, P., Liang, Z., 2013. Optimizing Cyclic CO2 Injection for Low- permeability Oil Reservoirs through Experimental Study. SPE 167193, SPE Unconventional Resources Conference Canada, 5-7 November, Calgary, Alberta, Canada.

25. Wilke, C.R. and Chang, P., 1955. Correlation of Diffusion Coefficients in Dilute Solution. AIChE Journal 1 (2), 264-270. DOI: 10.1002/aic.690010222.

26. Yu, Y., and Sheng, J.J. 2015. An Experimental Investigation of the Effect of Pressure Depletion Rate on Oil Recovery from Shale Cores by Cyclic $\mathrm{N}_{2}$ Injection. URTeC 2144010 was prepared for presentation at the Unconventional Resources Technology Conference held in San Antonio, Texas, USA, 20-22 July 2015. 